embryo and in tissue culture. Some years ago, one of $\mathrm{us}^{\mathrm{z}}$ demonstrated that in cultures of spinal ganglia of the chick, vacuoles taken in at the nerve tip rapidly travel along the fibre towards the cell-body, slthough in cultures of the spinal cord itself movement along the axons in the zone of outgrowth is irregular and without a general trend.

It is likely that trophic stimuli are transmitted within the developing nervous system by the passage of substances along the growing nerve fibres. The present evidence suggests that in some instances they travel in the same direction as that in which the nerve impulse will be conveyed in functional life.

\section{Arthur Huares}

Pierre André Tschumi

\section{Anatomy School, Cambridge. July 9.}

${ }^{1}$ Piatt, J., Biol. Rev., 23, 1 (1948).

${ }^{2}$ Hamburger, V., and Keefe, E. L., J. Exp. Zool., 96, 223 (1944).

${ }^{3}$ Tschumi, P. A., Rev. Suisse Zool., 61, 177 (1954).

- Lewis, P., and Hughes, A., in "Metabolism of the Nervous System" (Pergamon Press, London, in the press).

Levi-Montalcini, R., Ann. N.Y. Acad. Sei., 55, 330 (1952).

- Levi-Montalcini, R., and Cohen, S., Proc. U.S. Nat. Acad. Sci., 42 695 (1956).

' Hughes, A., J. Anat. Lond., 87, 150 (1953).

\section{Development of Isolated Female Larvæ of the Potato-Root Eelworm (Heterodera rostochiensis Woll.)}

TyLER ${ }^{1}$, following the observations of Byars ${ }^{2}$ and Gabriel ${ }^{3}$, conducted an experiment to determine whether the root-knot nematode, Heterodera marioni (Cornu) (now Meloidogyne sp.), could reproduce in the absence of males. Lines were maintained from isolated females through as many as twelve generations. Since Heterodera and Meloidogyne are closely related genera of the subfamily Heteroderinae, the possibility of such reproduction (parthenogenesis or syngonism) occurring in the potato-root eelworm, Heterodera rostochiensis Woll., was investigated.

Small tubers of Majestic potato were surfacesterilized and all 'eyes' removed. They were then cut into halves and a single larva of the potato-root eelworm was placed on each freshly cut surface. Each half-tuber was then buried in moist, autoclaved sand, one piece in each of a hundred $2 \frac{1}{2}$-in. pots, each covered with a glass lid and the sand kept moist by watering with a 20 p.p.m. copper sulphate solution. As controls, twelve similar tuber slices were prepared and about 2,000 larvæ added to each. The pots were kept at laboratory temperature $\left(20-22^{\circ} \mathrm{C}\right.$. $)$.

After four weeks the tubers were removed, washed free of adhering sand and examined for cysts. Further weekly examinations were made until the sixth week when, on two tuber slices, single developing females were seen. The control slices by this time bore numerous eysts, many in the yellow stage of development, and containing embryonating eggs. The single isolated cysts were maintained on the tuber slices until the tenth week, at which time they were still white, although a slight browning was detectable. They did not pass through the distinctive yellow stage. No eggs were found when the cysts were opened. 'Giant cells' were present in the tuber tissue associated with developing cysts.

These results are in agreement with those reported by Fassuliotis and Ellonby ${ }^{5}$, who found no em-

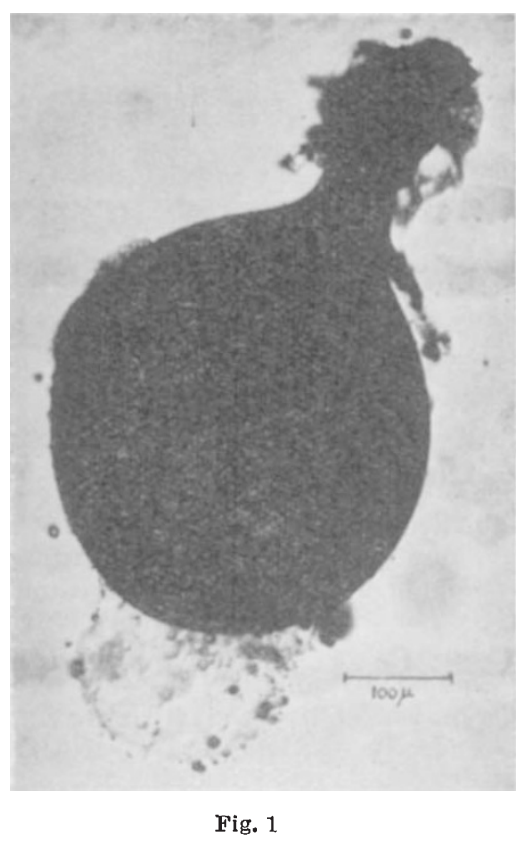

bryonated eggs in cysts developing on the roots of separate tomato plants and potato plants respectively to which a single larva had been added. They suggest that parthenogenesis does not occur.

One of the isolated females showed a gelatinous extrusion reminiscent of the egg sac found in other Heterodera spp., but not hitherto described in $H$. rostochiensis (Fig. 1).

This work is part of an investigation financed by the Agricultural Research Council. Thanks are due to Mr. S. G. Revell for the photograph of the cyst with the gelatinous extrusion.

T. D. Williams

School of Agriculture,

University of Cambridge. June 8.

1 Tyler, J., IIilgardia, 7 (10), 373 (1933).

a Byars, L. P., Phytopath., 4, 323 (1914).

${ }^{3}$ Gabriel, C., C.R. Soc. Biol., Paris, 95, 497 (1926).

- Fassuliotis, G., Phytopath., 47 (1), 11 (1957) (abstract).

$\checkmark$ Filenby, C., Nematologica, 2 (3), 250 (1957).

\section{Effect of Leaf Rust on Cereal Forage}

Few investigators have examined the effect of leaf rust on yield, chemical composition and nutritive value of cereal forage. This situation is unexpected in view of the large acreage of cereals devoted to sheep and cattle grazing in many countries. However, the reviews of Allen ${ }^{1}$ and of Chester ${ }^{2}$ indicate that invasion of a susceptible host by an obligate parasite such as leaf rust is accompanied by physiological disturbances mediated by chemical change. Murphy ${ }^{3}$ found that leaf rust infection of oats, harvested at the boot stage, reduced the yield of forage, altered the chemical composition and delayed maturity except where water-stress occurred. Murphy's observations may apply only to cereal forage at the boot stage of maturity and not necessarily to the much earlier stage of maturity at which cereal forages are grazed in New Zealand and elsewhere. Yarwood observed increased invasion of rust-infected tissue 